$\mathrm{Pl}$ at el et deri ved grouth fact or recept or al pha is essential for establ i shing a microenvi ronment that supports definitive eryt hropoi esi s

\begin{tabular}{|c|c|}
\hline 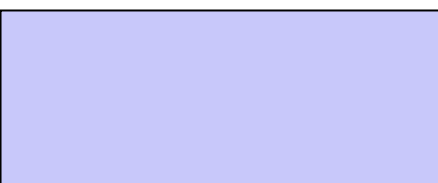 & $\begin{array}{l}\text { Li Wen- Li ng, Yamada Yoshi hi ro, Ueno Nasaya, } \\
\text { N shi kawa Sat omi, N shi kawa Shi n- I chi, } \\
\text { Takakur a Nobuyuki }\end{array}$ \\
\hline $\begin{array}{l}\text { j our nal or } \\
\text { publ i cat } i \text { on } t i t l e\end{array}$ & Jour nal of Bi ochemi stry \\
\hline vol une & 140 \\
\hline number & 2 \\
\hline page $r$ ange & $267-273$ \\
\hline year & 2006-08-01 \\
\hline URL & ht t p: //hdl . handl e. net /2297/14503 \\
\hline
\end{tabular}




\title{
Platelet Derived Growth Factor Receptor Alpha Is Essential for Establishing a Microenvironment That Supports Definitive Erythropoiesis
}

\author{
Wen-Ling Li ${ }^{1}$, Yoshihiro Yamada ${ }^{2}$, Masaya Ueno ${ }^{2}$, Satomi Nishikawa ${ }^{3}$, \\ Shin-Ichi Nishikawa ${ }^{3}$ and Nobuyuki Takakura ${ }^{1,2, *}$ \\ ${ }^{1}$ Department of Stem Cell Biology, Cancer Research Institute of Kanazawa University, 13-1 Takara-machi, \\ Kanazawa, 920-0934; ${ }^{2}$ Department of Signal Transduction, Research Institute for Microbial Diseases, \\ Osaka University, 3-1 Yamada-oka, Suita, Osaka 565-0871; and ${ }^{3}$ Laboratory for Stem Cell Biology, \\ RIKEN Center for Developmental Biology, 2-2-3 Minatojima Minami-machi, Kobe, Hyogo 650-0047
}

Received June 7, 2006; accepted June 15, 2006

\begin{abstract}
The hematopoietic system undergoes a qualitative change during the embryogenesis of most vertebrates. It is designated as the shift of primitive to definitive hematopoiesis and suitable microenvironment must be established to support this shift. While studying the role of platelet derived growth factor receptor $\alpha$ (PDGFR $\alpha$ ) in embryonic hematopoiesis, we found that it was expressed in a stromal cell component of liver, a major site of this shift, but not in the yolk sac, the site of primitive hematopoiesis. Thus, we considered that development of PDGFR $\alpha$ positive stromal cells is an essential requirement for this shift. Without PDFGR $\alpha$ positive cell component, erythropoiesis was suppressed in the culture of fetal liver. Moreover, injection of an antagonistic anti-PDGFR $\alpha$ monoclonal antibody during embryogenesis suppressed the production of definitive erythrocytes. These indicated that PDGF exerts its effect on a subset of stromal components to prepare a microenvironment that can support the definitive erythropoiesis.
\end{abstract}

Key words: erythropoiesis, erythropoietin, fetal liver, hematopoiesis, PDGF, PDGFR $\alpha$.

Abbreviations: mAb, monoclonal antibody; PDGFR $\alpha$, platelet derived growth factor receptor $\alpha$; CFU, colony forming unit.

Among about 200 cell types constituting the mammalian body, hematopoietic cells are generated most rapidly. In mice, fully mature erythrocytes are detectable at 8 days of gestation, when most other cell lineages still remain at intermediate stages. However, this early wave of hematopoiesis should undergo a qualitative change to establish the hematopoietic system that continues throughout life. This shift of primitive to definitive hematopoiesis is considered to be a cell autonomous process accompanying changes in the repertoire of key transcriptional regulator, such as the $c-m y b$ (1) and AML1/RUNX1 (2). However, a null mutation in erythropoietin (Epo) receptor gene $(3,4)$ and Epo gene (3) results in the failure of the production of adult type mature erythrocytes, indicating that the stromal cell components producing some factors to support hematopoiesis also play an essential role in the shift from primitive to definitive erythropoiesis. Although it has been widely believed that Epo is produced from the fetal liver and gradually production site of Epo shifts to the kidney, recent analysis revealed that Epo production is observed equally in the kidney as well as the fetal liver during early embryogenesis when fetal hematopoiesis starts (5). Therefore, erythropoiesis might be affected by Epo circulating in peripheral blood as well as it produced in

*To whom correspondence should be addressed at: Department of Signal Transduction, Research Institute for Microbial Diseases, Osaka University, 3-1 Yamada-oka, Suita, Osaka 565-0871. Tel: +81-6-6879-8316, Fax: +81-6-6879-8314, E-mail: ntakaku@ biken.osaka-u.ac.jp the fetal liver. Most importantly, erythropoiesis cannot be regulated only by a circulating Epo, but also by matrix proteins and another cytokine such as c-kit ligand, stem cell factor (SCF) (6) that are produced from stromal cell components in hematopoietic tissues.

A recent study of mice bearing a null mutation in platelet derived growth factor (PDGF)-B (7) or its receptor (PDGFR) $\beta$ (8) showed that most mutant embryos develop fatal hemorrhage before birth and this hemorrhage leads to erythroblastosis, macrocytic anemia and thrombocytepenia. Then anemia looked in those mutants was indicated as the secondary effect of hemorrhage. It was shown, however, anemia occurs in mutants before any obvious sign of bleeding. Then PDGF-B and PDGFR $\beta$ may be involved in the production of erythrocyte. Consistent with these functional studies, several investigators have detected PDGFR $\alpha$ in embryonic erythroblasts by in situ hybridization (9) or immunohistochemistry (10). Moreover, since c-Kit that belongs to the same family of receptor tyrosine kinases, are involved in the proliferation of hematopoietic stem cells (11), and differentiation of erythroblast (6). PDGFR $\alpha$, when expressed in the hematopoietic stem cell, should be able to take over the same function. Although mice carrying a targeted null mutation of PDGFRa gene were reported to show early embryonic lethality, hematological analysis has not been performed (12).

Previously, we established a monoclonal antibody (mAb) that recognizes the ligand-binding domain of murine $\operatorname{PDGFR} \alpha$. Hence, all functional PDGFR $\alpha$ should be recognized by this mAb (13-15). We then re-evaluated the role of 
PDGF signal in the embryonic hematopoiesis. In this study, we examined which cells in the hematopoietic tissues express PDGFR $\alpha$, and how they are involved in hematopoiesis. We showed that PDGFR $\alpha$ is not expressed in hematopoietic cells, whereas it is in the stromal/fibroblastic cells of embryonic hematopoietic tissues, and that PDGFR $\alpha$ plays a role for the shift from primitive to definitive erythropoiesis. This indicates that the generation and stimulation of $\mathrm{PDGFR} \alpha^{+}$stromal cell component play an essential role in establishing the microenvironment that supports the shift of erythropoiesis from primitive to the adult type.

\section{MATERIALS AND METHODS}

Animals-C57BL/6 mice and pregnant mice were purchased from Japan SLC Inc. (Shizuoka, Japan). The noon when a vaginal plug was detected was designated as embryonic day 0.5 of gestation (E0.5).

Immunohistochemistry-Tissue fixation procedures were basically as described (16). Fixed specimens were embedded in polyester wax and sectioned at $8 \mu \mathrm{m}$ as described (17). Immunostaining proceeded as described (15). In brief, sections were incubated with anti-c-Kit mAb, $\operatorname{ACK} 2(18,19)$, anti-PDGFR $\alpha$ mAb, APA5 (13-15), anti-flk1 mAb, AVAS12 (20), or anti-embryonic (21) or -adult (Cappel, Durham, NC) hemoglobin polyclonal antibody. Sections were incubated with a peroxidase conjugated secondary antibody, anti-rat-IgG antibody (Biosource, Camarillo, CA) for ACK2, APA5 and AVAS12, or anti-rabbit-IgG (Biosource) for both of anti-hemoglobin antibody and then color reaction was performed with diaminobenzidine (Dojin Chem., Kumamoto, Japan).

Procedure of whole-mount immunohistostaining was the same as described (15). In brief, the primary antibody was visualized by incubating $1 \mu \mathrm{g} / \mathrm{ml}$ peroxidase-conjugated anti-rat-Ig antibody (Biosource) overnight at $4^{\circ} \mathrm{C}$. After extensive washing, the specimens were soaked in PBS containing $0.1 \%$ Triton X-100, $0.05 \% \mathrm{NiCl}_{2}$ and $250 \mu \mathrm{g} / \mathrm{ml}$ diaminobenzidine (Dojin Chem.) for 10-30 minutes, then hydrogen peroxide was added to a final concentration of $0.01 \%$. The enzymatic reaction proceeded until the desired color-intensity was reached, then the specimens were rinsed 3-4 times in PBST.

Cell Preparation and Flow Cytometry-The fetal liver at E12.5 was dissociated by Dispase II (Boehringer Mannheim, Mannheim, Germany) and drawn through a $23 \mathrm{G}$ needle. Fetal liver cells $\left(5 \times 10^{5}\right)$ prepared from embryos (16) were suspended in $50 \mu \mathrm{l}$ of $5 \%$ FCS containing PBS. The cell-staining procedure for the flow cytometry was as described previously (17). The monoclonal antibodies (mAbs) used in immunofluorescence staining were anti$\beta 1$ integrin antibody, anti-lineage (ter119, Gr-1, Mac-1, B220, CD4, CD8) antibodies (all purchased from Pharmingen), anti-PDGFR $\alpha$ antibody (APA5) and anti-c-Kit antibody (ACK2). All mAbs were purified and conjugated with either FITC, PE (phycoerythrin), or biotin. Biotinylated antibodies were visualized with PE-conjugated streptavidin or APC-conjugated streptavidin (Pharmingen). Cells were incubated for $5 \mathrm{~min}$ on ice with 1:100 dilution of CD16/32 (Fc $\gamma$ III/II Receptor, (1:100) [Fcblock ${ }^{\text {TM }}$ ]; Pharmingen) prior to staining with primary antibody. The stained cells were analyzed by FACS calibur (Becton
Dickinson, San Jose, CA) and sorted by EPICS Flow cytometer (ALTRA: Beckman Coulter, San Jose, CA). Sorted TER119 positive erythroid cells from APA5 or control antibody injected fetal liver were attached on glass and stained with anti-embryonic hemoglobin antibody as described previously (17).

Cell Culture and CFU-c Analysis-Single cell suspension from E12.5 fetal liver was stained with anti-PDGFR $\alpha$ antibody, and then PDGFR $\alpha$ positive fraction was eliminated by cell sorting. $1 \times 10^{5}$ sorted fetal liver cells not containing PDGFR $\alpha$ positive cells and fetal liver cells containing both PDGFR $\alpha$ negative and positive cells once sorted for making even condition in cell preparation were cultured on 12 well fibronectin coated dishes (Becton Dickinson, Bedford, MA) in RPMI (Sigma, St. Louis, MO) containing 10\% FCS in the presence or absence of $10 \mathrm{ng} / \mathrm{ml}$ PDGF (Peprotech, London, UK) at $37^{\circ} \mathrm{C}$ in a $5 \% \mathrm{CO}_{2}$ incubator for 7 days. For the analysis of Epo induction from fetal liver cells, fetal liver cells were harvested after $24 \mathrm{~h}$ and RNA was extracted. After culturing, all cells were harvested and subjected to the colony formation unit in culture (CFU-c) assay as described previously (22). Colony containing only erythrocyte was counted as CFU-E after 4 days of culturing. The total number of hematopoietic colonies [i.e., CFUgranulocyte $(\mathrm{G})$, macrophage (M) and granulocyte/macrophage (GM)] was counted as another CFU-c after 7 days of culturing.

RT-PCR Analysis-The RNeasy Mini kit (Qiagen $\mathrm{GmbH}$, Hilden, Germany) was used for isolation of total RNA from cells from fetal liver. Total RNA was reverse transcribed using the RT for PCR kit (Clontech, Palo Alto, CA). The cDNA was amplified using Advantage Polymerase Mix (Clontech) in a GeneAmp PCR system model 9700 (Perkin-Elmer Inc., Norwalk, CT) by 30 to 35 cycles. The sequences of the gene-specific primers for RT-PCR were as follows: $5^{\prime}$-EPO (TAGAAGTTTGGCAAGGCCTG), 3'-EPO (CGTGTACAGCTTCAGTTTCC), 5' -TPO (CCTCTTCTTGAGCTTGCAAC), 3'-TPO (AGCCCATGAGTTCCATTCAC), 5'-SCF (TAACCCTCAACTATGTCGCC), 3'-SCF (TCACTAGTGTCAGATGCCAC), $5^{\prime}$ - $\beta$-actin (CCTAAGGCCAACCGTGAAAAG), $3^{\prime}$ - $\beta$-actin (TCTTCATGGTGCTAGGAGCCA). Each cycle consisted of denaturation at $94^{\circ} \mathrm{C}$ for $30 \mathrm{~s}$, and annealing/extension at $70^{\circ} \mathrm{C}$ for $4 \mathrm{~min}$.

Maternal Injection of Monoclonal Antibodies-Pregnant mice were given an intravenous injection of anti-PDGFR $\alpha$ mAb, APA5 (2 mg) daily from E9.5 to E13.5. Rat antimurine IL-7 receptor mAb, A7R34 (23) was used as an isotype-matched control and injected as described above. The mice injected with antibodies were sacrificed at E15.5 by cervical dislocation and embryos were fixed with cold $4 \%$ paraformaldehyde containing PBS ( $\mathrm{pH} 7.4$ ). Fixed specimens were embedded into polyester wax and sectioned at $5 \mu \mathrm{m}$.

\section{RESULTS}

Expression of PDGFR $\alpha$ in Fetal Hematopoietic TissuesTo gain insight on the expression of PDGFR $\alpha$ in the fetal tissues, embryos were whole mount immunohistostained by the anti-PDGFR $\alpha$ mAb, APA5, with particular focus in the yolk sac where hematopoiesis has been demonstrated to take place. Because previous studies (24-27) suggest that c-Kit is expressed and functioning in the 
fetal hematopoietic stem cells, embryos were also stained with the anti-c-Kit mAb, ACK2.

Although it was suggested that hematopoietic cells in the blood island express PDGFR $\alpha$, we could not detect PDGFR $\alpha$ expression in any cells in the yolk sac (Fig. 1A) in embryonic day (E) 9.5. In contrast, blood islands in the yolk sac were stained as scattered dots by c-Kit ${ }^{+}$cells (Fig. 1B). In this stage, yolk sac was organized by the nest of Flk-1 positive endothelial cells (Fig. 1C).

To further analyze the cells expressing PDGFR $\alpha$ in the hematopoietic organ, we immunostained the sections of E12.5 liver. PDGFR $\alpha$ staining was most intense in the mesenchymal cells surrounding the fetal liver. In addition, we also detected PDGFR $\alpha^{+}$cells scattered in the parenchyma of developing fetal liver (Fig. 1D). These are bipolar fibroblastic cells and different from the round cells stained by anti-c-Kit mAb, ACK2 (Fig. 1E). Moreover, PDGFR $\alpha$ staining remarkably differed from that by anti-Flk1 mAb that marks vascular endothelium (Fig. 1F).

To confirm that no hematopoietic cell lineages in the embryonic tissues express PDGFR $\alpha$, we performed flowcytometric analysis of fetal liver cells from E12.5 embryos using a number of hematopoietic cell markers. As shown in Fig. 2, PDGFR $\alpha$ cells are very few among whole fetal liver cells $(0.4 \%)$ as observed in immunohistostaining of fetal liver section and PDGFR $\alpha$ cells were undetectable in TER $119^{+}$erythroblasts, which supposedly express PDGFR $\alpha$. Moreover, there was no PDGFR $\alpha^{+}$cell among the hematopoietic lineage cells expressing CD4, CD8, B220, Mac-1 Gr-1. In the hematopoietic stem cells designated as Lin (mixture of B220, Mac-1, TER119, CD4, 8, and Gr-1) negative and c-Kit positive fraction, we could not
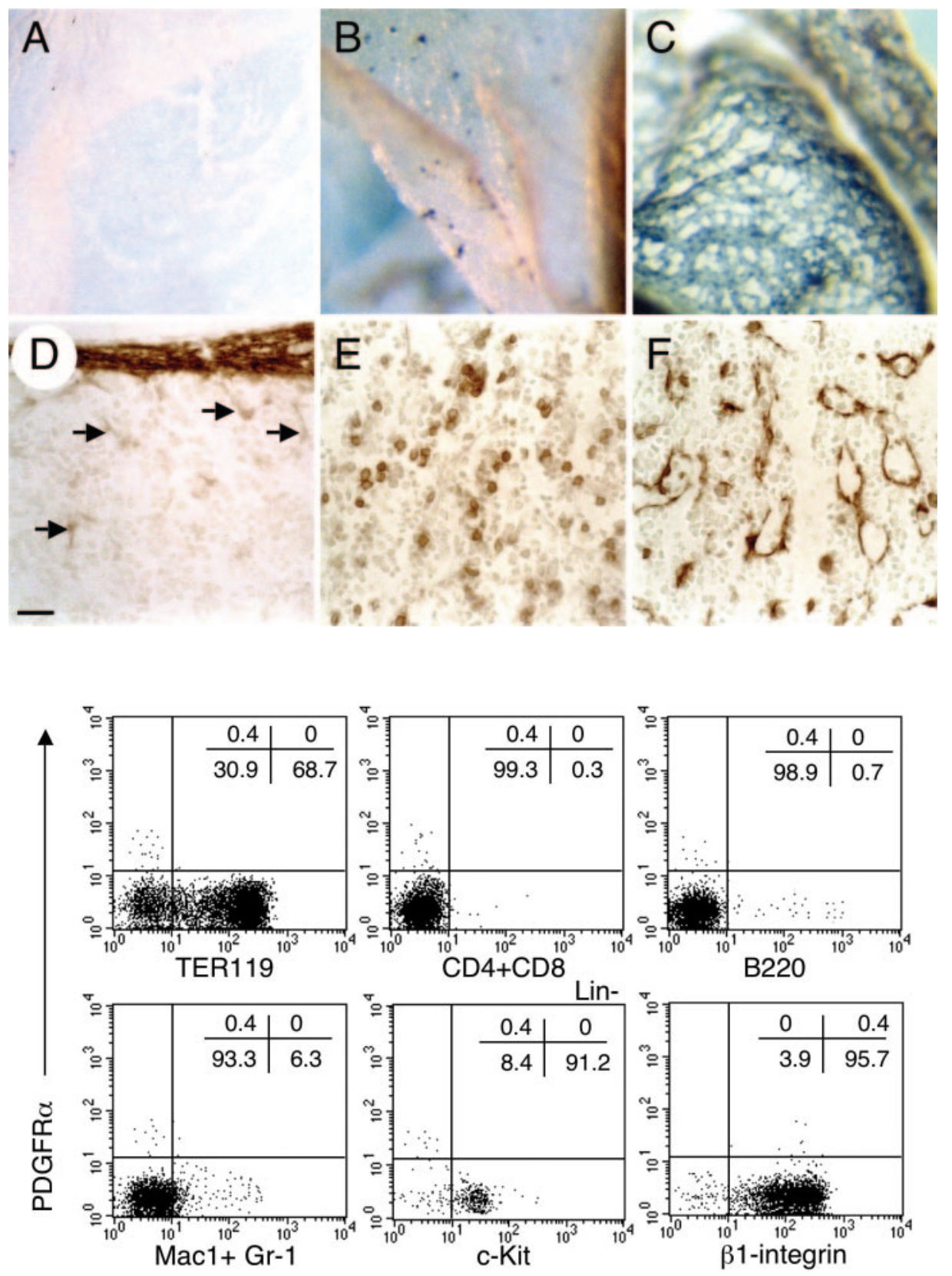

Fig. 1. PDGFRa expression in the fetal liver. Whole-mount staining in yolk sac of E9.5 embryos $(\mathrm{A}-\mathrm{C})$ with $\mathrm{mAbs},(\mathrm{A})$ anti-PDGFR $\alpha$ antibody, (B) anti-c-Kit antibody, and (C) anti-Flk-1 antibody. In the yolk sac, PDGFR $\alpha$ expression is not found (A), whereas c-Kit expressing spots are scattered throughout yolk sac (B) and Flk-1 positive cells form vascular nests (C). Immunohistochemical staining of sections from E12.5 fetal liver. (D) PDGFR $\alpha$, (E) c-Kit and (F) Flk-1 expression. Arrows in (D) indicate PDGFR $\alpha$ positive cells in parenchyma of fetal liver. Bar indicates $25 \mu \mathrm{m}$.
Fig. 2. Flow cytometric analysis of the fetal liver. Fetal liver cells from E12.5 embryo were stained with anti-PDGFR $\alpha$ and TER119, mixture of anti-CD4 and anti-CD8 mAbs, B220, mixture of Mac-1 and Gr-1, anti-c-Kit mAb, or anti- $\beta 1$ integrin $\mathrm{mAb}$. Mixture of antiMac-1,-B220, -TER119,-CD4,-CD8 and Gr.1 mAbs was used as lineage markers. The vertical and horizontal lines indicate the threshold of fluorescence intensity of negative control staining. The percentage of cells in each quadrant is shown in the top right-hand corner of each panel. 


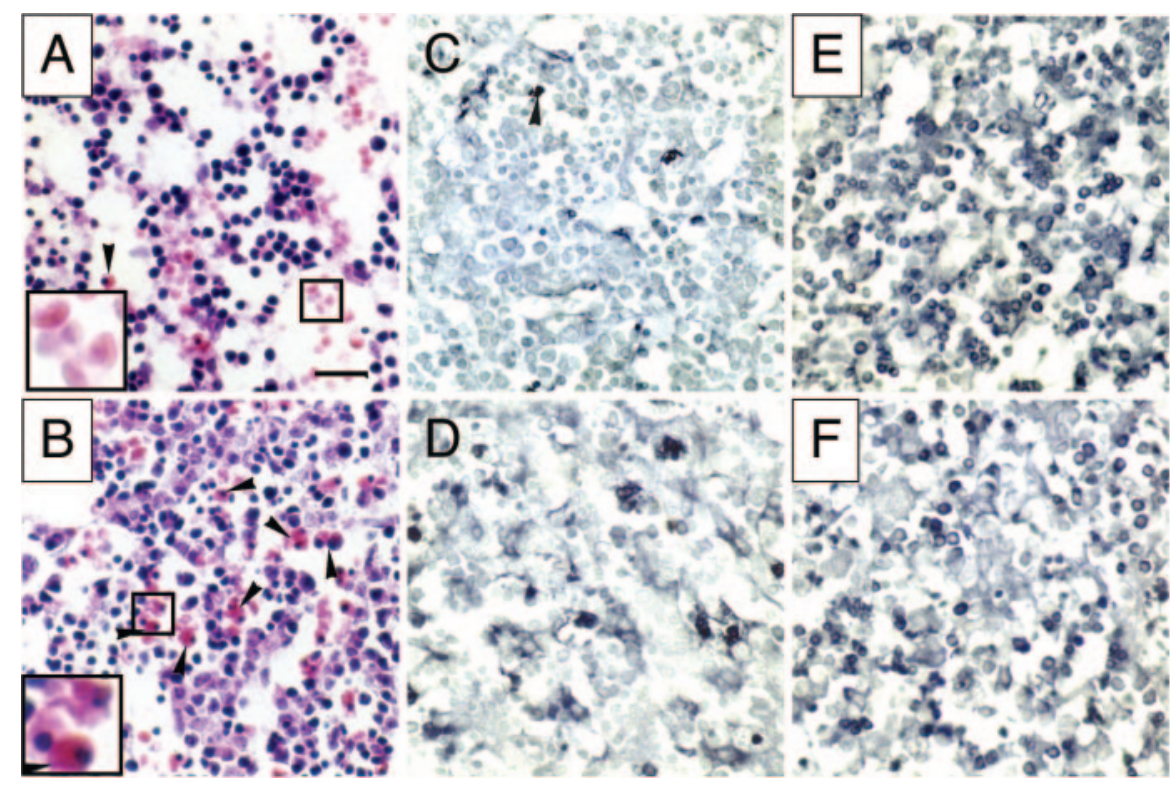

Fig. 3. Injection of anti-PDGFR $\alpha$ antibody suppressed the shift from the primitive to definitive erythropoiesis. (A, C, E) anti-IL7R mAb, A7R34 (2 mg) as an isotype matched control or (B, D, F) AntiPDGFR $\alpha$ mAb, APA5 (2 mg) was injected intravenously into pregnant mice every day from E9.5 to E13.5, and embryos were dissected at E15.5. The sections of the livers were either hematoxylin-eosin stained (A, B) or immunohistostained with anti-embryonic hemoglobin (C, D) or anti-adult hemoglobin (E, F). Arrow heads in (A) and (B) indicate nucleated erythrocytes. Insets in (A) and (B) are high power views indicated by box, respectively. Insets in (A) and (B) show enucleated erythrocytes and nucleated erythrocytes, respectively. Bar indicates $25 \mu \mathrm{m}$.

observe the expression PDGFR $\alpha$, whereas almost all PDGFR $\alpha$ cells express $\beta 1$ integrin, one of the mesenchymal marker. Moreover, we could not detect PDGFR $\alpha$ cells of hematopoietic lineage in the yolk sac (data not shown). These results indicated that PDGFR $\alpha$ is not expressed in any embryonic hematopoietic lineage cells, whereas it was expressed in the stromal cell component.

Anti-PDGFR $\alpha$ Antibody Suppressed the Production of Adult type Erythrocytes in Embryos-To investigate the role of PDGFR $\alpha$ in hematopoiesis, we used anti-PDGFR $\alpha$ antibody that blocks the binding of PDGFR $\alpha$ to both PDGF-A and PDGF-B $(13,14)$ and observed fetal liver hematopoiesis. Pregnant mice were given an intravenous injection of $2 \mathrm{mg}$ anti-PDGFR $\alpha$ antibody every day from E9.5 to E13.5, and the embryos were examined on E15.5. As shown in Fig. 3, the numbers of mature enucleated erythrocytes in the fetal liver treated with anti-PDGFR $\alpha$ antibody (Fig. 3B) were small compared with those treated with control Ig, anti-IL7 receptor (R) mAb (Fig. 3A) and there were many nucleated erythrocytes (arrow heads) in anti-PDGFR $\alpha$ antibody treated fetal liver (Fig. 3B). When hemoglobin staining was performed, many erythrocytes in the fetal liver treated with anti-PDGFR $\alpha$ antibody were of the fetal type stained with anti-embryonic and anti-adult type hemoglobin antibody (Fig. 3, D and F). We sorted TER119 positive erythroid cells from the fetal liver and counted the number of embryonic hemoglobin positive fetal type erythroid cells among total erythroid cells. Result revealed that $37 \pm 7 \% \quad(n=5)$ among total TER119 positive erythroid cells was of fetal type. On the other hand, most erythrocytes in the embryo that had been given control anti-IL7R mAb expressed adult type hemoglobin but not fetal hemoglobin (Fig. 3, C and E). As described above, we observed the ratio of fetal type erythroid cells among total TER119 positive erythroid cells obtained by cell sorting. Result revealed that $5 \pm 1 \%$ ( $n=5$ ) was of fetal type. No substantial defect was detected in cells of other lineages confirmed by May-GruenwaldGiemsa staining and flow cytometric analysis (data not shown).

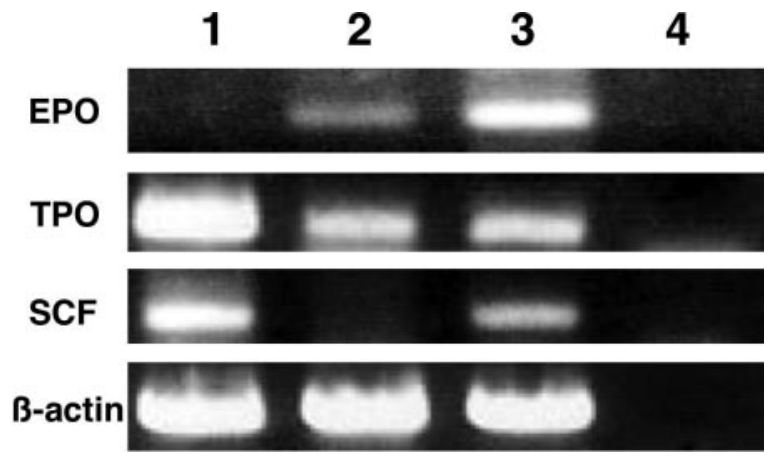

Fig. 4. Expression of erythropoietin in PDGFRa positive cells in the fetal liver. Expression of erythropoietin (EPO), thrombopoietin (TPO), and stem cells factor (SCF) was examined by RT-PCR analysis in (1) PDGFR $\alpha$ negative fraction, (2) PDGFR $\alpha$ positive fraction, and (3) whole cells from E12.5 fetal liver. (4) Distilled water. $\beta$-actin was used for internal control.

This result suggested that the PDGFR $\alpha$ signal is involved in the generation of adult type erythrocytes.

PDFGR $\alpha$ Positive Cells Are the Source of Erythropoietin in the Fetal Liver and Support Definitive ErythropoiesisEpo and Epo receptor-deficient mice die in utero due to a marked reduction in the number of committed fetal liver derived erythroid progenitors, resulted in lack of enucleated mature erythrocyte development $(3,4)$. The fetal liver acts as the primary site of synthesis of Epo $(5,28)$. Therefore, we observed the expression of Epo in PDFGR $\alpha$ positive cells from the fetal liver. As shown in Fig. 4, Epo expression was observed in PDGFR $\alpha$ positive cells but not in PDGFR $\alpha$ negative cells in the fetal liver. On the other hand, in case of expression of other growth factors such as thrombopoietin (TPO) and stem cell factor (SCF), which are involved in generation of hematopoietic progenitors, PDGFR $\alpha$ negative fraction expressed both of TPO and SCF but PDGFR $\alpha$ positive fraction did not express SCF. These indicated that PDGFR $\alpha$ positive cells in the fetal 

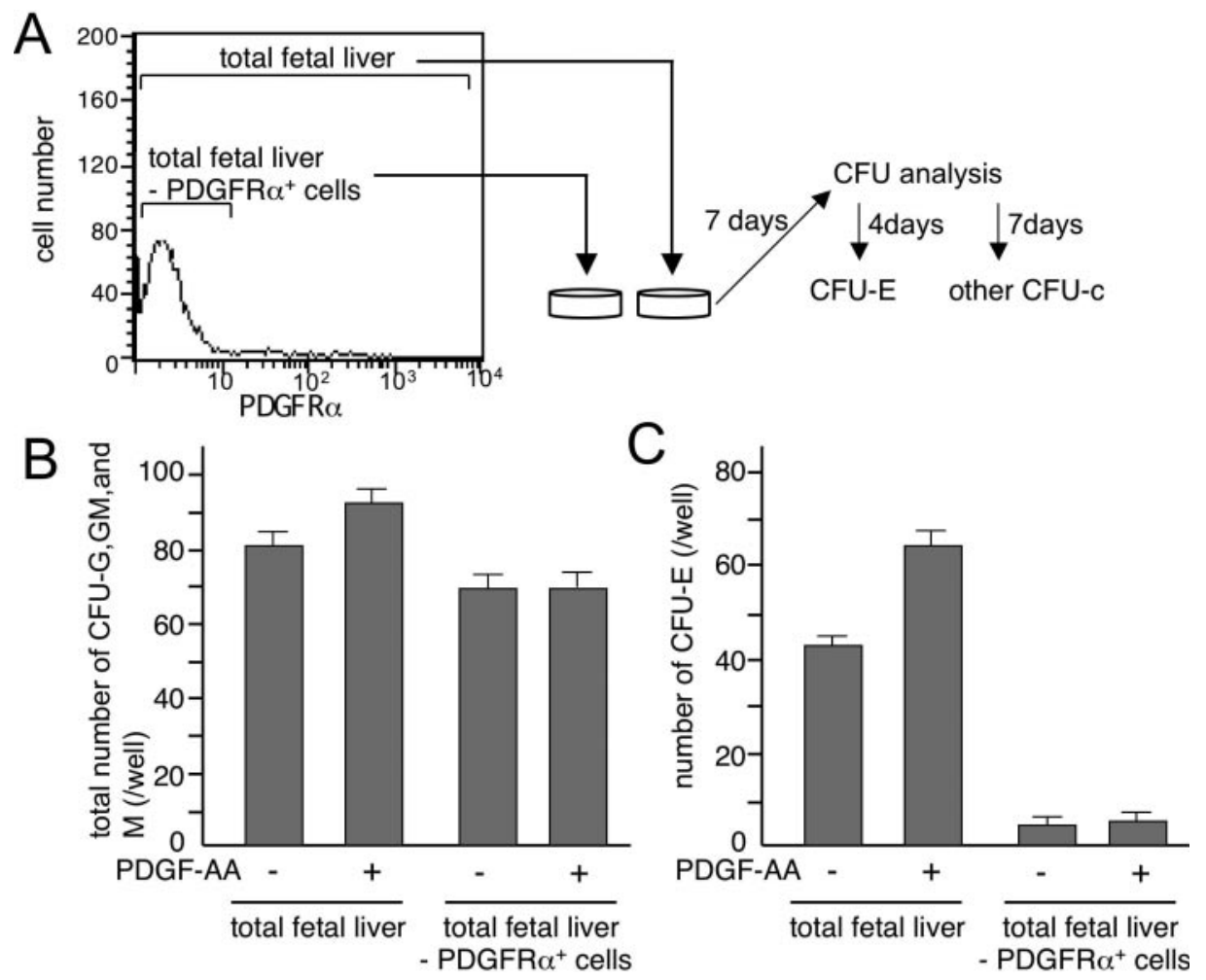

Fig. 5. PDGFR $\alpha$ positive cells in the fetal liver can support erythropoiesis. (A) FACS analysis of PDGFR $\alpha$ positive cells existing in the mouse fetal liver at E12.5 and schematic presentation of the step wise culture system with fetal liver cells of E12.5 mouse embryos. Total fetal liver cells (total fetal liver) or PDGFR $\alpha$ negative fetal liver cells (total liver - PDGFR $\alpha^{+}$cells) were cultured for 7 days in the presence or absence of PDGF-AA and transferred to semi-solid culture condition. The number of CFU-E or another CFU-c (CFU-G, GM, and $\mathrm{M})$ was counted on day 4 or day 7 , respectively. (B) Comparison of the total number of CFU-G, GM, and M derived from culture of fetal liver cells as above in the presence or absence of PDGFR $\alpha$ positive cells or PDGF-AA. (C) Comparison of the total number of CFU-E derived from culture of fetal liver cells as above in the presence or absence of PDGFR $\alpha$ positive cells or PDGF-AA. liver can support definitive erythropoiesis by producing Epo, and that blockade of PDGFR $\alpha$ signaling by antiPDGFR $\alpha$ antibody injection affected the generation of enucleated mature erythrocyte. However, it is unclear whether total administration of PDGFR $\alpha$ antibody directly affects the PDGFR $\alpha$ positive cells in the fetal liver or not and PDGFR $\alpha$ signaling in the fetal liver is actually involved in erythropoiesis. To overcome these issues, we cultured fetal liver cells in the presence or absence of PDGFR $\alpha$ positive cells or PDGF-AA and observed the development of erythrocyte progenitors by the analysis of colony forming unit (CFU)-erythrocyte (E) formation (Fig. 5A)

Results showed that the number of CFU-containing granulocytes (G), macrophage (M), granulocyte/macrophage (GM) slightly increased by the addition of PDGF-AA in the presence of PDGFR $\alpha$ positive cells. Moreover, depletion of PDGFR $\alpha$ positive cells from total fetal liver cells slightly reduced the generation of CFU-G, M, and GM formation. However, in both cases, there are no significant differences statistically (Fig. 5B). On the other hand, in case of CFU-E formation (Fig. 5C), the number of CFU-E increased by the addition of PDGF-AA in the presence of PDGFR $\alpha$ positive cells. Moreover, depletion of PDGFR $\alpha$ positive cells from total fetal liver cells dramatically reduced the generation of CFU-E.

Finally, we observed whether or not PDGF-AA or -BB affect the Epo expression in the culture of fetal liver cells. As shown in Fig. 6, both of PDGF-AA and PDGF-BB induced the Epo expression in fetal liver cells.

Taken together, these indicated that PDGFR signal via PDGFR $\alpha$ positive cells are required for the generation of definitive erythrocytes in the fetal liver.

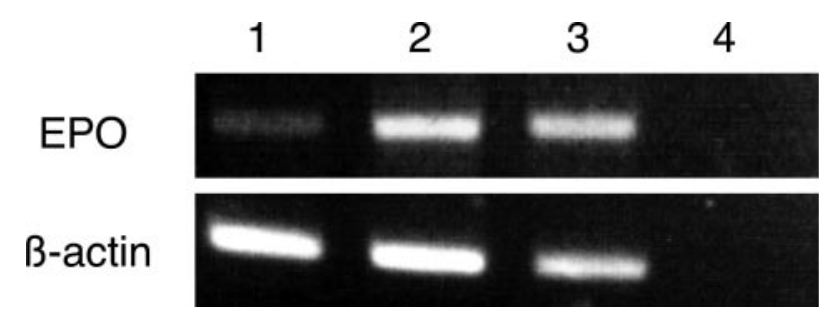

Fig. 6. Expression of erythropoietin in fetal liver cells stimulated by PDGF. Expression of erythropoietin (EPO) was examined by RT-PCR analysis in cultured fetal liver cells in the absence of PDGF (1), in the presence of $10 \mathrm{ng} / \mathrm{ml}$ PDGF-AA (2), in the presence of $10 \mathrm{ng} / \mathrm{ml}$ PDGF-BB. (4) Distilled water. $\beta$-actin was used for internal control.

\section{DISCUSSION}

The question addressed in this study was how PDGF is involved in the embryonic erythropoiesis. Studies of mice bearing a null mutation of PDGF-B (7) and its receptor (8) indicated that these signals might be involved in the fetal erythropoiesis, as anemia is a key phenotype of these mutant embryos. In this study, we demonstrated that PDGFR $\alpha$ positive cells in the fetal liver regulate definitive erythropoiesis. Adult type erythrocyte precursors may express PDGFR $\alpha$ that functions in their proliferation. Although several studies support this notion $(9,29)$, the results presented here argue against the expression of PDGFR $\alpha$ in hematopoietic cells at any stage of embryogenesis. We showed this by immunohistostaining and by flowcytometry. It is difficult to explain the discrepancy between our results and those of others. As our mAb recognizes the 
ligand-binding site of PDGFR $\alpha$, functional PDGFR $\alpha$ molecules should be recognized by our mAb. Thus, the positive signal found in embryonic erythrocytes by other groups may be due to either the nonfunctional, truncated molecule, or non-specific background. Indeed, fetal erythrocytes display higher background upon in situ hybridization.

We then examined which cells express PDGFR $\alpha$ and how PDGFR $\alpha$ positive cells are involved in hematopoiesis. The present results suggested that stromal cells rather than erythrocyte progenitors express PDGFR $\alpha$. Using a mAb specific to Flk1 that is expressed in the vascular endothelium, we demonstrated that PDGFR $\alpha^{+}$cells are different from the vascular endothelium. Thus, the effect of PDGF on erythropoietic progenitors should be transferred indirectly to the erythrocyte progenitors via PDGFR $\alpha^{+}$stromal cells in the microenvironment. However, an anti-PDGFR $\alpha$ antibody injection into adult mice did not suppress the adult erythropoiesis (data not shown). This suggested that the PDGF signal plays an essential role in establishing the microenvironment to initiate adult type erythropoiesis, whereas the established adult intramarrow microenvironment is maintained by different mechanisms.

A phenotype found in the anti-PDGFR $\alpha$ antibody injected mouse was similar with mice that bear a null mutation either of erythropoietin (3) or erythropoietin receptors $(3,4)$, as maturation arrest of definitive erythroid progenitor cells and complete lack of mature enucleated erythrocyte are key phenotypes. Though anti-PDGFR $\alpha$ antibody injected mouse had a few enucleated mature erythrocytes, primitive erythrocytes were abundantly observed in E15.5 fetal liver of anti-PDGFR $\alpha$ antibody injected embryo. Moreover, the production of erythropoietin starts in fetal liver at around E13 earlier than in the kidney (30, 31). This suggests the possibility that PDGFR $\alpha$ provides an important signal for establishing the stromal component that can secrete Epo.

In this context, it is notable that PDGFR $\alpha$ expression in the stromal cell component is found in the fetal liver, but not in the yolk sac. Hence, the first wave of erythropoiesis is independent from the PDGFR $\alpha$ signal and therefore all the erythrocytes produced from yolk sac remain primitive. However, as soon as active hematopoiesis shifts to the fetal liver where the microenvironment is stimulated by PDGF, the shift to adult type erythropoiesis would be facilitated. In this respect, stromal cells in the hematopoietic site can provide a molecular cue to shift to the adult type erythrocytes. In deed, we found that Epo expression is observed in PDGFR $\alpha$ positive cell component but not in PDGFR $\alpha$ negative cell component of E12.5 fetal liver and we found that Epo expression is induced by PDGF-AA or PDGF-BB directly in in vitro culture of fetal liver cells. If the induction of Epo at the site of hematopoiesis is a role of PDGFR $\alpha$, then the anti-PDGFR $\alpha$ antibody injection would not suppress adult erythropoiesis because the site of Epo production shifts to the kidney in adult (32).

It has been reported that Epo mRNA in the liver is expressed in the fibroblast-like Ito cells and it in the kidney is expressed in proximal tubular cells (5). We tried to isolate PDGFR $\alpha$ positive cells from the fetal liver and to culture those cells. However, we could not succeed to culture and maintain the survival of PDGFR $\alpha$ positive cells by means of generally used in vitro culture system. An attempt to isolate PDGFR $\alpha^{+}$stromal cell components is currently underway in our laboratory to understand the characteristic differences between PDGFR $\alpha^{+}$cells in the fetal liver and proximal tubular cells in the kidney for the regulation of Epo production. Whether suppression of PDGFR $\alpha$ signal decreases the expression of Epo or affects the CFU-E formation or not is under way using the isolated PDGFR $\alpha^{+}$cells from fetal liver or such isolated PDGFR $\alpha^{+}$cells with hematopoietic progenitors from fetal liver.

We thank Dr. T. Atsumi (RIKEN Tsukuba Institute, Ibaraki, 305-0074, Japan) for providing us antibody against embryonic hemoglobin. We thank Ms. Y. Shimizu, Ms. K. Ishida, Ms. M. Sato, and Mrs. Y. Nakano for technical assistance. This work was supported by the Japanese Ministry of Education, Culture, Sports, Science and technology, and the Japan Society for Promotion of Science.

\section{REFERENCES}

1. Mucenski, M.L., McLain, K., Kier, A.B., Swerdlow, S.H., Schreiner, C.M., Miller, T.A., Pietryga, D.W., Scott, W.J., and Potter, S. (1991) A functional $c-m y b$ gene is required for normal murine fetal hepatic hematopoiesis. Cell 65, 677-689

2. Okuda, T., Deursen, J.V., Hiebert, S.W., Grosveld, G., and Downing, J.R. (1996) AML1, the target of multiple chromosomal translocations in human leukemia, is essential for normal fetal liver hematopoiesis. Cell 84, 321-330

3. Wu, H., Liu, X., Jaenish, R., and Lodish, H.F. (1995) Generation of committed erythroid BFU-E and CFU-E progenitors does not require erythropoietin or the erythropoietin receptor. Cell 83, 59-67

4. Lin, C.-S., Lim, S.-K., D'Agati, V., and Costantini, F. (1996) Differential effects of an erythropoietin receptor gene disruption on primitive and definitive erythropoiesis. Genes Dev. 10, 154-164

5. Moritz, K.M., Lim, G.B., and Wintour, E.M. (1997) Developmental regulation of erythropoietin and erythropoiesis. Am. J. Physiol. 273, 1829-1844

6. Munugalavadla, V., and Kapur, R. (2005) Role of c-Kit and erythropoietin receptor in erythropoiesis. Crit. Rev. Oncol. Hematol. 54, 63-75

7. Levéen,P.,Pekny, M., Gebre-Medhin, S., Swolin, B.,Larsson,E., and Betsholtz, C. (1994) Mice deficient for PDGF B show renal, cardiovascular, and hematological abnormalities. Genes Dev. 8, 1875-1887

8. Soriano, P. (1994) Abnormal kidney development and hematological disorders in PDGF $\beta$-receptor mutant mice. Genes Dev. 8, 1888-1896

9. Orr-Urtreger, A., and Lonai, P. (1992) Platelet-derived growth factor-A and its receptor are expressed in separate, but adjacent cell layers of the mouse embryo. Development $\mathbf{1 1 5}$, 1045-1058

10. Bidwell, M.C., Eitzman, B.A., Walmer, D.K., Mclachlan, J.A., and Gray, K.D. (1995) Analysis of messenger ribonucleic acid and protein for the ligands and receptors of the plateletderived growth factor signaling pathway in the placenta, extraembryonic membranes, and uterus during the latter half of murine gestation. Endocrinology 136, 5189-5201

11. Mackarehtschian, K., Hardin, J.D., Moore, K.A., Boast, S., Goff, S.P., and Lemischka, I.R. (1995) Targeted disruption of the flk2/flt3 gene leads to deficiencies in primitive hematopoietic progenitors. Immunity 3, 147-161

12. Soriano, P. (1997). The PDGF alpha receptor is required for neural crest cell development and for normal patterning of the somites. Development 124, 2691-2700

13. Takakura, N., Yoshida, H., Kunisada, T., Nishikawa, S., and Nishikawa, S.-I. (1996) Involvement of platelet derived growth 
factor receptor- $\alpha$ in hair canal formation. J. Inv. Dermatol. 107, 770-777

14. Fruttiger, M., Calver, A.R., Krüger, W.H., Mudhar, H.S., Michalovich, D., Takakura, N., Nishikawa, S.I., and Richardson, W.D. (1996) PDGF mediates a neuron-astrocyte interaction in the developing retina. Neuron 17, 1117-1131

15. Takakura, N., Yoshida, H., Ogura, Y., Kataoka, H., Nishikawa, S., and Nishikawa, S.-I. (1997) PDGFR $\alpha$ expression during mouse embryogenesis: Immunolocalization analyzed by whole mount immuno-histostaining using the monoclonal anti-mousePDGFR $\alpha$ antibody APA5. J. Histochem. Cytochem. 45, 883-893

16. Takakura, N., Watanabe, T., Suenobu, S.,Yamada, Y., Noda, T., Ito, Y., Satake, M., and Suda, T. (2000) A role for hematopoietic stem cells in promoting angiogenesis. Cell 102, 199-209

17. Takakura, N., Huang, X.L., Naruse, T., Hamaguchi, I., Dumont, D.J., Yancopoulos, G.D., and Suda, T. (1998) Critical role of the TIE2 endothelial cell receptor in the development of definitive hematopoiesis. Immunity 9, 677-686, 1998

18. Nishikawa, S., Kusakabe, M., Yoshinaga, K., Ogawa, M., Hyashi, S.I., Kunisada, T., Era, T., Sakakura, T., and Nishikawa, S.-I. (1991) In utero manipulation of coat color formation by a monoclonal anti-c-kit antibody: two distinct waves of c-kit dependency during melanocyte development. $E M B O$ J. 10, 2111-2118

19. Ogawa, M., Matsuzaki, Y., Nishikawa, S., Hayashi, S.I., Kunisada, T., Sudo, T., Kina, T., Nakauchi, H., and Nishikawa. S.-I. (1991) Expression and function of c-kit in hemopoietic progenitor cells. J. Exp. Med. 174, 63-71

20. Kataoka, H., Takakura, N., Nishikawa, S., Tsuchida, K., Kodama, H., Kunisada, T., Risau, W., Kita, T., and Nishikawa, S.I. (1997) Expressions of PDGF receptor alpha, c-Kit and Flk1 genes clustering in mouse chromosome 5 define distinct subsets of nascent mesodermal cells. Dev. Growth Differ. 39, $729-740$

21. Miwa, Y., Atsumi, T., Imai, N., and Ikawa, Y. (1991) Primitive erythropoiesis of mouse teratocartinoma stem cells PCC3/A/1 in serum-free medium. Development 111, 543-549

22. Okamoto, R., Ueno, M., Yamada, Y., Takahashi, N.,Sano, H., Suda, T., and Takakura, N. (2005) Hematopoietic cells regulate the angiogenic switch during tumorigenesis. Blood 105, $2757-2763$
23. Sudo, T., Nishikawa, S., Ohno, N., Akiyama, N., Tamakoshi, M., Hisahiro, Y., and Nishikawa, S.-I. (1993) Expression and function of the interleukin 7 receptor in murine lymphocytes. Proc. Natl. Acad. Sci. USA 90, 9125-9129

24. Ogawa, M., Nishikawa, S., Ikuta, K., Yamamura, F., Naito, M., Takahashi, K., and Nishikawa, S.I. (1998) B cell ontogeny in murine embryo studied by a culture system with the monolayer of a stromal cell clone, ST2: B cell progenitor develops first in the embryonal body rather than in the yolk sac. EMBO J. 7, 1337-1343

25. Orr-Urtreger, A., Avivi, A., Zimmer, Y., Givol, D., Yarden, Y., and Lonai, Y.P. (1990) Developmental expression of c-kit, a proto-oncogene encoded by the locus. Development $\mathbf{1 0 9}$, 911-923

26. Palacios, R., and Nishikawa, S.-I. (1992) Developmentally regulated cell surface expression and function of c-kit receptor during lymphocyte ontogeny in the embryo and adult mice. Development 115, 1133-1147

27. Ikuta, K., and Weissman, I. (1992) Evidence that hematopoietic stem cells express mouse c-kit but do not dependent on steel factor for their generation. Proc. Natl. Acad. Sci. USA 89 , 1052-1506

28. Maxwell, P.H., Ferguson, D.J., Osmond, M.K., Pugh, C.W., Heryet, A., Doe, B.G., Johnson, M.H., and Ratcliffe, P.J. (1994) Expression of a homologously recombined erythopoietin-SV40 T antigen fusion gene in mouse liver: evidence for erythropoietin production by Ito cells. Blood $\mathbf{8 4}$, 1823-1830

29. Dainiak, N., Davies, G., Kalmanti, M., Lawler, J., and Kulkarni, V. (1983) Platelet-derived growth factor promotes proliferation of erythropoietic progenitor cells in vitro. J. Clin. Invest. 71, 1206-1214

30. Koury, M.J., Bondurant, M.C., Graber, S.E., and Sawyer, S.T. (1998) Erythropoietin messenger RNA levels in developing mice and transfer of ${ }^{125}$ I-erythropoietin by placenta. J. Clin. Invest. 82, 154-159

31. Koury, S.T., Bondurant, M.C., Koury, M.J., and Semenza, G.L. (1991) Localization of cells producing erythropoietin in murine liver by in situ hybridization. Blood 77, 2497-2503

32. Koury, S.T., Bondurant, M.C., and Koury, M.J. (1998) Localization of erythropoietin synthesizing cells in murine kidneys by in situ hybridization. Blood 71, 524-527 